Pacific Journal of Mathematics

THE SOLUTION OF A STIELTJES-VOLTERRA INTEGRAL 


\title{
THE SOLUTION OF A STIELTJES-VOLTERRA INTEGRAL EQUATION FOR RINGS
}

\author{
Burrell W. Helton
}

For a triple $(h, K, g)$ of functions and an interval $[a, x]$, the author defines a subdivision-refinement-type limit $V(a, x ; h, K, d g)$ of the set $\{V(D, h, K, \Delta g)\}$ of determinants, where each subdivision $D=\left\{x_{i}\right\}_{0}^{n}$ of $[a, x]$ defines an $n \times n$ determinant of the set and each determinant has the form

$\left|\begin{array}{llll}h_{1}+h_{0} K_{10} \Delta g_{1} & -1 & 0 & 0 \\ h_{2}+h_{0} K_{20} \Delta g_{1} & K_{21} \Delta g_{2} & -1 & 0 \\ h_{3}+h_{0} K_{30} \Delta g_{1} & K_{31} \Delta g_{2} & K_{32} \Delta g_{3} & -1 \\ h_{4}+h_{0} K_{40} \Delta g_{1} & K_{41} \Delta g_{2} & K_{42} \Delta g_{3} & K_{43} \Delta g_{4}\end{array}\right|$

The following theorem is proved. If $f, g, h$ and $K$ are functions to a ring and $g$ has bounded variation on $[a, b]$, then $(f, K, g) \in$ $O A^{*}$ and $f(x)=h(x)+(L) \int_{a}^{x} f(t) K(x, t) d g(t)$ on $[a, b]$ iff $(h, K, g) \in O M^{*}$ and $f(x)=V(a, x ; h, K, d g)$ on $[a, b]$. The $O A^{*}$ and $O M^{*}$ sets are defined and sufficient conditions are proved for $(f, K, g) \in O A^{*}$ and $(h, K, g) \in O M^{*}$, and for the existence of the limit $V(a, x ; h, K, d g)$, and for $V(a, x ; h, K, d g)=h(x)-(L) \int_{a}^{x} h(t) d V(t, x ; 1, K, d g)$.

Although the Volterra equation $f(x)=h(x)+\int_{a}^{x} f(t) K(x, t) d t$ has been studied in depth by many persons, it seems that only Hinton [3], Reneke [4] [5] and Bitzer [1] [2] have published papers on the Volterra integral equation in which the integral is a subdivision-refinement-type Stieltjes integral. In this paper the solution of the Volterra equation and the development of the related properties do not depend on a Picard expansion or on the above quoted references. So far as the author has been able to determine, this subdivision-refinement definition of the solution $V(a, x ; h, K, d g)$ of the Volterra equation has not been published previously.

Definitions and notations. The symbol $R$ denotes the set of real numbers and $N$ is a ring which has a multiplicative identity element 1 and a norm $|\cdot|$ with respect to which $N$ is complete and $|1|=1 ; f, g$ and $h$ are functions from $R$ to $N$ and $K$ is a function from $R X R$ to $N$. Also, $d g \in O B^{0}$ on $[a, b]$ means $g$ has bounded variation on $[a, b]$. All 
integrals are of the subdivision-refinement-type limits; the approximating sum for $(L) \int E(t) d g(t)$ is $\Sigma E\left(t_{i-1}\right)\left[g\left(t_{i}\right)-g\left(t_{i-1}\right)\right]$ and for (R) $\int E(t) d g(t)$ is $\Sigma E\left(t_{i}\right)\left[g\left(t_{i}\right)-g\left(t_{i-1}\right)\right]$. If no misunderstanding is likely, the symbols $K_{i j}, f_{i}$ and $\Delta g_{i}$ will be used for $K\left(x_{i}, x_{j}\right), f\left(x_{i}\right)$ and $g\left(x_{i}\right)$ $g\left(x_{i-1}\right)$, respectively.

If $\left\{a_{i j}\right\}_{i, j=1}^{n}$ is a sequence of elements of $N$ and $p$ and $q$ are integers such that $1 \leqq p \leqq q \leqq n$, then the symbol $\left|a_{i j}\right|_{p}^{q}$ denotes the determinant

$$
\left|\begin{array}{ccc}
a_{p p} & \cdots & a_{p q} \\
\cdots & \cdots & \cdots \\
a_{q p} & \cdots & a_{q q}
\end{array}\right|
$$

and is defined by the sum of the $(q-p+1)$ ! products obtained as follows: (1) each term of the sum is a product, or the negative of a product, which contains one and only one element from each row and each column of $\left|a_{i j}\right|_{p}^{q} ;$ (2) the factors of each term are ordered so that the second subscripts appear in the order $p, p+1, \cdots, q$; and (3) the product or the negative of a product is used as a term according as the number of inversions of the first subscripts is even or odd. Note that the usual theorems pertaining to determinants will hold, except where multiplicative commutativity is needed in the proofs. Also, if $A=\left|a_{i j}\right|_{1}^{n}$, then $|A|$ denotes the norm of $A$ and, if $1 \leqq p \leqq n, A_{p},{ }^{*} A_{p}$ and ${ }^{*} A_{p k}$ denote the determinants defined as follows: $A_{p}=\left|a_{i j}\right|_{1}^{p},{ }^{*} A_{p}=\left|a_{i j}\right|_{p}^{n}, A_{0}=1,{ }^{*} A_{n+1}=$ 1 , and if $1 \leqq k \leqq p$, then ${ }^{*} A_{p k}$ is the determinant obtained by replacing the first column of $\left|a_{i j}\right|_{p}^{n}$ with the column $\left\{a_{i k}\right\}_{i=p}^{n}$ of elements of $\left\{a_{i j}\right\}_{i, j=1}^{n}$.

$A=\left|a_{i j}\right|_{1}^{n}$ is a Volterra determinant means $\left\{a_{i j}\right\}_{i, j=1}^{n}$ is a sequence such that $a_{i j}=-1$ for $j=i+1$ and $a_{i j}=0$ for $j>i+1 . A=\left|a_{i j}\right|_{1}^{n}$ is a delta determinant defined by the sequences $\left\{c_{i j}\right\}_{i, j=1}^{n}$ and $\left\{d_{j}\right\}_{j=0}^{n}$ means $A$ is a Volterra determinant and $a_{i j}=c_{i j}\left(d_{j}-d_{j-1}\right)$ for $1 \leqq j \leqq i \leqq n$.

If $D=\left\{x_{i}\right\}_{0}^{n}$ is a subdivision of a number interval $[a, b]$, then $V(D, h, K, \Delta g)$ denotes the $n \times n$ Volterra determinant $\left|a_{i j}\right|_{1}^{n}$ such that $a_{i 1}=h\left(x_{i}\right)+h\left(x_{0}\right) K\left(x_{i}, x_{0}\right)\left[g\left(x_{1}\right)-g\left(x_{0}\right)\right]$ for $i=1,2, \cdots, n$ and $a_{i j}=$ $K\left(x_{i}, x_{j-1}\right)\left[g\left(x_{j}\right)-g\left(x_{j-1}\right)\right]$ for $1<j \leqq i \leqq n$. If no misunderstanding is likely, $V(D)$ will be used to denote $V(D, h, K, \Delta g)$.

The limit $V(a, b ; h, K, d g)$ exists means there is an element $J$ of $N$ such that if $\epsilon>0$ then there is a subdivision $D$ of $[a, b]$ such that if $D^{\prime}$ is a refinement of $D$ then $\left|J-V\left(D^{\prime}, h, K, \Delta g\right)\right|<\epsilon$. The symbol $V(a, b ; h, K, d g)$ will be used to denote this limit $J$.

If $m>1$, the number $M$ is an $m$-bound for $V(,,, \Delta g)$ on $[a, b]$ means $M \geqq m$ and, if $|h|<m$ on $[a, b]$ and $|K|<m$ on $[a, b] \times[a, b]$ and $D$ is a subdivision of a subinterval of $[a, b]$ and $A=\left|a_{i j}\right|_{1}^{n}=$ $V(D, h, K, \Delta g)$, then $|A|<M$ and each of $\left|A_{p}\right|,\left.\right|^{*} A_{p} \mid$ and $\left|{ }^{*} A_{p j}\right|$ is less than $M$ for $1 \leqq p \leqq n$ and $1 \leqq j \leqq p$. 
The triple $(f, K, g) \in O A^{*} \quad$ on $[a, b]$ means that (L) $\int_{a}^{x} f(t) K(x, t) d g(t)$ exists for $x \in[a, b]$ and if $\epsilon>0$ then there is a subdivision $D$ of $[a, b]$ such that, if $\left\{t_{i}\right\}_{0}^{n}$ is a refinement of $D$ and $0<p \leqq n$ and $x=t_{p}$, then

$\left|(L) \int_{a}^{x} f(t) K(x, t) d g(t)-\Sigma_{1}^{p} f\left(t_{i-1}\right) K\left(x, t_{i-1}\right)\left[g\left(t_{i}\right)-g\left(t_{i-1}\right)\right]\right|<\epsilon$.

The triple $(h, K, g) \in O M^{*}$ means $V(a, x ; h, K, d g)$ exists for $x \in$ $[a, b]$ and if $\epsilon>0$ then there is a subdivision $D$ of $[a, b]$ such that, if $\left\{x_{i}\right\}_{0}^{n}$ is a refinement of $D$ and $0<p \leqq n$ and $H=\left\{x_{i}\right\}_{0}^{p}$, then

$$
\left|V\left(a, x_{p} ; h, K, d g\right)-V(H, h, K, \Delta g)\right|<\epsilon .
$$

The triple $(1, K, g) \in O M^{* *}$ on $[a, b]$ means $V(x, b ; 1, K, d g)$ exists for $x \in[a, b]$ and if $\epsilon>0$ then there is a subdivision $D$ of $[a, b]$ such that, if $\left\{x_{i}\right\}_{0}^{n}$ is a refinement of $D$ and $0 \leqq p<n$ and $H=\left\{x_{i}\right\}_{p}^{n}$, then

$$
\left|V\left(x_{p}, b ; 1, K, d g\right)-V(H, 1, K, \Delta g)\right|<\epsilon,
$$

where 1 denotes the identity function.

In the following three definitions, $G(x, y)=\int_{x}^{y}|d g|$.

$\int_{a}^{b} \int_{a}^{b}|d K||d g||d g|=0$ means if $\epsilon>0$ then there is a subdivision $D$ of $[a, b]$ such that, if $\left\{x_{i}\right\}_{0}^{n}$ is a refinement of $D$, then

$$
\sum_{i=1}^{n} \sum_{j=1}^{n} M_{i j} G\left(x_{i-1}, x_{i}\right) G\left(x_{j-1}, x_{j}\right)<\epsilon,
$$

where, for each $i$ and $j, M_{i j}$ is the lub of $\left|K\left(x_{i-1}, x_{j-1}\right)-K(x, y)\right|$ for $x_{i-1} \leqq x<x_{i}$ and $x_{j-1} \leqq y<x_{j}$.

If $a \leqq p \leqq b, \int_{a}^{b}|d K(p, x)||d g(x)|=0$ means if $\epsilon>0$ then there is a subdivision $D$ of $[a, b]$ such that, if $\left\{x_{i}\right\}_{0}^{n}$ is a refinement of $D$, then $\sum_{1}^{n} M_{i} G\left(x_{i-1}, x_{i}\right)<\epsilon$, where, for each $i, M_{i}$ is the lub of $\mid K\left(p, x_{i-1}\right)-$ $K(p, x) \mid$ for $x_{i-1} \leqq x<x_{i}$.

$$
\int_{a}^{b}|d K(, x)||d g(x)|=0 \text { uniformly on }[a, b] \text { means if } \epsilon>0 \text { then }
$$

there is a subdivision $D$ of $[a, b]$ such that, if $\left\{x_{i}\right\}_{0}^{n}$ is a refinement of $D$ and $a \leqq p \leqq b$, then $\Sigma_{1}^{n} M_{i} G\left(x_{i-1}, x_{i}\right)<\epsilon$, where, for each $i, M_{i}$ is the lub of $\left|K\left(p, x_{i-1}\right)-K(p, x)\right|$ for $x_{i-1} \leqq x<x_{i}$.

The set $S$ of functions is bounded uniformly on $[a, b]$ means there is a number $M$ such that, if $f \in S$ and $x \in[a, b]$, then $|f(x)|<M$. The set $S$ 
of functions is quasicontinuous uniformly on $[a, b]$ means $S$ is bounded uniformly on $[a, b]$ and if $\epsilon>0$ then there is a subdivision $D=\left\{x_{i}\right\}_{0}^{n}$ of $[a, b]$ such that, if $f \in S$ and $0<i \leqq n$ and $x_{i-1}<r<t<x_{i}$, then $|f(r)-f(t)|<\epsilon$.

THEOREMS. In Theorems $1-5$ we develop properties of the Volterra determinant. Theorem 6 gives the solution to the Stieltjes-Volterra integral equation.

THEOREM 1. If $A=\left|a_{i j}\right|_{1}^{n}$ is a Volterra determinant and $0<p \leqq n$, then

(a) $A=a_{11}^{*} A_{2}+{ }^{*} A_{21}$;

(b) $A=\sum_{i=1}^{n} a_{i 1}{ }^{*} A_{i+1}=\sum_{j=1}^{n} A_{j-1} a_{n j}$;

(c) if $0<j \leqq p$, then ${ }^{*} A_{p j}=a_{p j}{ }^{*} A_{p+1}+{ }^{*} A_{p+1, j}=\sum_{i=p}^{n} a_{i j}{ }^{*} A_{i+1}$;

(d) $A=\sum_{i=1}^{p} A_{j-1}{ }^{*} A_{p j}=\sum_{i=1}^{p} A_{j-1}\left(\sum_{i=p}^{n} a_{i j}{ }^{*} A_{i+1}\right)$;

(e) if $p<n$ and $B=\left|b_{i j}\right|_{1}^{n}$ and $b_{p, p+1}=0$ and $b_{i j}=a_{i j}$ otherwise, then $B=\sum_{j=1}^{p} A_{j-1} a_{p j}{ }^{*} A_{p+1} ;$ and

(f) if $a_{i j}=0$ whenever $1<j \leqq p$ and $j \leqq i \leqq n$, then $A={ }^{*} A_{p 1}$.

Each item in Theorem 1 can be proved using the definition of a determinant or by mathematical induction. Note that $A_{0}=1$ and ${ }^{*} A_{n+1}=$ 1 .

THEOREM 2. If $A$ is a delta determinant defined by the sequences $\left\{c_{i j}\right\}_{1}^{n}$ and $\left\{g_{i}\right\}_{0}^{n}$ and $\left|c_{i j}\right| \leqq m$ for $i, j=1,2, \cdots, n$, then

$$
|A| \leqq m\left|g_{1}-g_{0}\right| I I_{2}^{n}\left(1+m\left|g_{i}-g_{i-1}\right|\right) \text {. }
$$

Proof. (by induction) If $A$ is a $2 \times 2$ delta determinant defined by $\left\{c_{i j}\right\}_{1}^{2}$ and $\left\{g_{i}\right\}_{0}^{2}$, then

$$
\begin{aligned}
|A| & =\left|c_{11} \Delta g_{1} c_{22} \Delta g_{2}+c_{21} \Delta g_{1}\right| \\
& \leqq\left|\Delta g_{1}\right|\left(\left|c_{11}\right|\left|c_{22}\right|\left|\Delta g_{2}\right|+\left|c_{21}\right|\right) \leqq m\left|\Delta g_{1}\right|\left(1+m\left|\Delta g_{2}\right|\right) .
\end{aligned}
$$

Suppose that the theorem is true for $n=p$ and $A$ is a $(p+1) \times(p+1)$ delta determinant defined by $\left\{c_{i j}\right\}_{1}^{p+1}$ and $\left\{g_{i}\right\}_{0}^{p+1}$; then $A=c_{11} \Delta g_{1}{ }^{*} A_{2}+{ }^{*} A_{21}$ (Th. 1a). Since ${ }^{*} A_{2}$ and ${ }^{*} A_{21}$ are $p \times p$ delta determinants which have $\Delta g_{2}$ and $\Delta g_{1}$ as factors of each element of the first columns, respectively, then

$$
\begin{aligned}
|A| \leqq & \left|c_{11}\right|\left|\Delta g_{1}\right|\left|{ }^{*} A_{2}\right|+\left|{ }^{*} A_{21}\right| \\
\leqq & \left|c_{11}\right|\left|\Delta g_{1}\right|\left[m\left|\Delta g_{2}\right| I I_{3}^{p+1}\left(1+m\left|\Delta g_{i}\right|\right)\right] \\
& +m\left|\Delta g_{1}\right| I I_{3}^{p+1}\left(1+m\left|\Delta g_{i}\right|\right) \\
\leqq & m\left|\Delta g_{1}\right| I I_{2}^{p+1}\left(1+m\left|\Delta g_{i}\right|\right) .
\end{aligned}
$$


THEOREM 3. If $m>1$ and $d g \in O B^{0}$ on $[a, b]$, then there is a number $M$ such that $M$ is an $m$-bound for $V(,,, \Delta g)$ on $[a, b]$.

Proof. Suppose that $m>1$ and $k$ is a bound for $|g|$ on $[a, b]$. Let $M=P+Q$, where $P=m^{2}(1+2 k)$ and $Q=P m \int_{a}^{b}|d g| \exp \int_{a}^{b} m|d g|$. Let $D=\left\{x_{i}\right\}_{i=0}^{n}$ be a subdivision of a subinterval of $[a, b]$ and let $K$ and $h$ be functions such that $m$ bounds $|K|$ on $[a, b] \times[a, b]$ and $|h|$ on $[a, b]$. Let $A=\left|a_{i j}\right|_{1}^{n}=V(D, h, K, \Delta g)$; then ${ }^{*} A_{i+1}$ is a delta determinant for $i=1,2, \cdots, n-1$. Hence, for $i=1,2, \cdots, n$ and $1<j \leqq i, \quad P=m^{2}$ $+2 m^{2} k>\left|K_{i, j-1}\right|\left|\Delta g_{j}\right| \geqq\left|a_{i j}\right|$ and $P=m^{2}+2 m^{2} k>\left|h_{i}\right|+\left|h_{0}\right|\left|K_{i 0}\right|\left|\Delta g_{1}\right|$ $\geqq\left|a_{i 1}\right|$; hence, if $0<i \leqq n$ and $0<j \leqq n$, then $\left|a_{i j}\right|<P$. Therefore,

$$
\begin{aligned}
|A| & \leqq\left.\sum_{i=1}^{n-1}\left|a_{i 1}\right|\right|^{*} A_{i+1}|+| a_{n 1} \mid \\
& <\left.\sum_{1}^{n-1} P\right|^{*} A_{i+1} \mid+P \\
& \leqq \sum_{1}^{n-1} P m\left|\Delta g_{i+1}\right| I_{j=i+2}^{n}\left(1+m\left|\Delta g_{j}\right|\right)+P \\
& \leqq P m \int_{a}^{b}|d g| \exp \int_{a}^{b} m|d g|+P=Q+P=M .
\end{aligned}
$$

Similarly, $\left|A_{p}\right|<M,\left.\right|^{*} A_{p} \mid<M$ and $\left|{ }^{*} A_{p j}\right|<M$ for $1 \leqq p \leqq n$ and $j=1,2, \cdots, p$.

THEOREM 4. If $\left\{f_{i}\right\}_{1}^{n}$ and $\left\{a_{i j}\right\}_{1}^{n}$ are sequences of elements of $N$ and $A=\left|a_{i j}\right|_{1}^{n}$ is an $n \times n$ Volterra determinant, then the following statements are equivalent.

(1) $f_{1}=a_{11}$ and $f_{i}=a_{i 1}+\sum_{j=2}^{i} f_{j-1} a_{i j}$ for $1<i \leqq n$; and

(2) $f_{i}=A_{i}$ for $0<i \leqq n$.

Proof. If $0<i \leqq n$, it follows from Theorem $1 \mathrm{~b}$ that $A_{i}=$ $a_{i 1}+\sum_{j=2}^{i} A_{j-1} a_{i j}$; therefore, $1 \rightarrow 2$ by induction and $2 \rightarrow 1$ by induction.

THEOREM 5. If $g$ is a function and $m$ is a number such that $m>1$ and $d g \in O B^{0}$ on $[a, b]$, then there is a number $Q$ such that, if $m$ bounds the functions $H$ and $K$ on $[a, b] \times[a, b]$ and $h$ and $k$ on $[a, b]$ and $D=\left\{x_{i}\right\}_{0}^{n}$ is a subdivision of a subinterval of $[a, b]$, then

$$
|A-B| \leqq Q \sum_{p=1}^{n} \sum_{j=1}^{p}\left|a_{p j}-b_{p j}\right|\left|g\left(x_{p+1}\right)-g\left(x_{p}\right)\right|,
$$

where $A=\left|a_{i j}\right|_{1}^{n}=V(D, h, H, \Delta g), \quad B=\left|b_{i j}\right|_{1}^{n}=V(D, k, K, \Delta g) \quad$ and $\left|\Delta g_{n+1}\right|=1$.

Proof. Let $g$ be a function and $m$ be a number such that $d g \in O B^{0}$ on $[a, b]$ and $m>1$. It follows from Theorem 3 that there is a number $M$ 
which is an $m$-bound for $V(,,, \Delta g)$ on $[a, b]$. Let $Q=$ $M m \exp \left(m \int_{a}^{b}|d g|\right)$. Let $H, K, h$ and $k$ be functions which are bounded by $m$ on $[a, b]$.

First we will consider a special case. Suppose that $D=\left\{x_{i}\right\}_{0}^{n}$ is a subdivision of a subinterval of $[a, b], A=\left|a_{i j}\right|_{1}^{n}=V(D, h, H, \Delta g), B=$ $\left|b_{i j}\right|_{1}^{n}=V(D, k, K, \Delta g), 1 \leqq p \leqq n$, and $a_{i j}=b_{i j}$ for $i \neq p$; then $A-B=$ $\left|a_{i j}\right|_{1}^{n}-\left|b_{i j}\right|_{1}^{n}$ is an $n \times n$ determinant $C=\left|c_{i j}\right|_{1}^{n}$ such that $c_{i j}=a_{i j}$ for $i \neq p$, $c_{p j}=a_{p j}-b_{p j}$ for $1 \leqq j \leqq p$ and $c_{p, p+1}=0$ for $p<n$.

If $p=n$, then

$$
\begin{aligned}
|A-B| & =|C|=\left|\sum_{j=1}^{n} C_{j-1} c_{n j}\right| \\
& \leqq \sum_{j=1}^{n} M\left|a_{n j}-b_{n j}\right| \leqq Q \sum_{j=1}^{n}\left|a_{n j}-b_{n j}\right|\left|\Delta g_{n+1}\right| .
\end{aligned}
$$

If $1 \leqq p<n$, then

$$
\begin{aligned}
|A-B| & =|C|=\left|\sum_{j=1}^{p} C_{j-1} c_{p j}{ }^{*} C_{p+1}\right| \\
& \leqq \sum_{j=1}^{p} M\left|a_{p j}-b_{p j}\right|\left|{ }^{*} C_{p+1}\right| \\
& \leqq \sum_{j=1}^{p} M\left|a_{p j}-b_{p j}\right| m\left|\Delta g_{p+1}\right| \exp \int_{a}^{b} m|d g| \\
& \leqq Q \sum_{j=1}^{p}\left|a_{p j}-b_{p j}\right|\left|\Delta g_{p+1}\right| .
\end{aligned}
$$

We will now prove the general case. Suppose that $D=\left\{x_{i}\right\}_{0}^{n}$ is a subdivision of $[a, b]$ and that $A$ and $B$ are the determinants $A=\left|a_{i j}\right|_{1}^{n}=$ $V(D, h, H, \Delta g)$ and $B=\left|b_{i j}\right|_{1}^{n}=V(D, k, K, \Delta g)$. There exists a sequence $\left\{R_{p}\right\}_{0}^{n}$ of $n \times n$ determinants such that $A=R_{0}, B=R_{n}$, and $A-B=$ $\sum_{p=1}^{n}\left(R_{p-1}-R_{p}\right)$ and such that, if $a<p \leqq n$ and $R_{p-1}=\left|u_{i j}\right|_{1}^{n}$ and $R_{p}=$ $\left|v_{i j}\right|_{1}^{n}$, then $u_{i j}=v_{i j}$ for $i \neq p$. For each integer $p, 0<p \leqq n, R_{p-1}-R_{p}$ is the difference of two determinants as defined in the special case above; therefore,

$$
\begin{aligned}
|A-B| & =\left|\sum_{p=1}^{n}\left(R_{p-1}-R_{p}\right)\right| \leqq \sum_{p=1}^{n}\left|R_{p-1}-R_{p}\right| \\
& \leqq \sum_{p=1}^{n} Q \sum_{j=1}^{p}\left|a_{p j}-b_{p j}\right|\left|\Delta g_{p+1}\right| .
\end{aligned}
$$

THEOREM 6. Given. $K$ is a bounded function from $R \times R$ to $N$ and $f$, $h$ and $g$ are functions from $R$ to $N$ and $d g \in O B^{0}$ on $[a, b]$. Conclusion. The following statements are equivalent:

(1) $(f, K, g) \in O A^{*}$ on $[a, b]$ and, if $x \in[a, b]$, then

$$
f(x)=h(x)+(L) \int_{a}^{x} f(t) K(x, t) d g(t)
$$


(2) $(h, K, g) \in O M^{*}$ on $[a, b]$ and, if $x \in[a, b]$, then $f(x)=$ $V(a, x ; h, K, d g)$.

Proof of $1 \rightarrow 2$. Suppose that $m$ is a bound for $K$ and $\epsilon>0$. Since $(f, K, g) \in O A^{*}$ on $[a, b]$, there exists a subdivision $H$ of $[a, b]$ such that, if $H^{\prime}=\left\{x_{t}\right\}_{0}^{n}$ is a refinement of $H$ and $0<i \leqq n$ and $x=x_{t}$, then

$$
\left|(L) \int_{a}^{x} f(t) K(x, t) d g(t)-\sum_{j=1}^{i} f\left(x_{j-1}\right) K\left(x, x_{l-1}\right) \Delta g_{\jmath}\right|<\epsilon / M,
$$

where $M=4\left[m \int_{a}^{b}|d g| \exp \int_{a}^{b} m|d g|+1\right]$. Let $x \in(a, b]$ and let $H^{\prime}=$ $\left\{x_{\imath}\right\}_{0}^{n}$ be any refinement of $H$ such that $x \in H^{\prime}$; let $x=x_{p}$ and $D=\left\{x_{i}\right\}_{0}^{p}$, where $0<p \leqq n$. For each integer $i$ such that $0<i \leqq p$ there exists an element $\epsilon_{l} \in N$ such that

$$
\begin{aligned}
& f\left(x_{\imath}\right)=h\left(x_{\imath}\right)+(L) \int_{a}^{x_{t}} f(t) K\left(x_{\imath}, t\right) d g \\
& =h\left(x_{t}\right)+\sum_{l=1}^{l} f\left(x_{I-1}\right) K\left(x_{t}, x_{I-1}\right)\left[g\left(x_{l}\right)-g\left(x_{I-1}\right)\right]+\epsilon_{t} \\
& =\left(h_{\imath}+\epsilon_{\imath}+f_{0} K_{l, 0} \Delta g_{1}\right)+\sum_{\jmath=2}^{i} f_{\jmath-1} K_{t, j-1} \Delta g_{l},
\end{aligned}
$$

where $\sum_{f=2}^{1}()=0$. Let $\epsilon$ be a function such that $\epsilon(a)=0$ and $\epsilon\left(x_{\imath}\right)=\epsilon_{l}$, for $i=1,2, \cdots, p$. Let $V(D, h+\epsilon, K, \Delta g)=\left|v_{\imath \jmath}\right|_{1}^{p}$; then $\left|v_{\imath \jmath}\right|_{1}^{p}$ is a Volterra determinant such that $v_{l 1}=h_{l}+\epsilon_{l}+h_{0} K_{t, 0} \Delta g_{1}$ for $i=1,2, \cdots, p$, and $v_{\imath \jmath}=K_{t, j-1} \Delta g_{\text {I }}$ for $1<j \leqq i \leqq p$. Hence, $f_{1}=v_{11}$ and $f_{t}=v_{t 1}+\sum_{j=2}^{i} f_{l-1} v_{i j}$ for $1<i \leqq p$. Therefore,

$$
\begin{aligned}
f(x) & =f\left(x_{p}\right)=V(D, h+\epsilon, K, \Delta g) \\
& =V(D, h, K, \Delta g)+V(D, \epsilon, K, \Delta g) .
\end{aligned}
$$

Let $A=\left|a_{i j}\right|_{1}^{p}=V(D, \epsilon, K, \Delta g)$, then ${ }^{*} A_{t+1}$ is a delta determinant for $i=1,2, \cdots, p-1$, and

$$
\begin{aligned}
|A| & =\left|\Sigma_{1}^{p} \epsilon_{l}^{*} A_{i+1}\right| \\
& \leqq \Sigma_{1}^{p-1}\left|\epsilon_{l}\right| m\left|\Delta g_{t+1}\right| \exp \int_{a}^{b} m|d g|+\left|\epsilon_{p}\right|<\epsilon,
\end{aligned}
$$

Therefore, $|f(x)-V(D, h, K, \Delta g)|=|A|<\epsilon$. Since $x$ is an arbitrary element of $(a, b]$ and $H^{\prime}$ is an arbitrary refinement of $H$ containing $x$, it follows that $V(a, x ; h, K, d g)=f(x)$ for $x \in[a, b]$ and that $(h, K, g) \in O M^{*}$ on $[a, b]$.

Proof of $2 \rightarrow 1$. Suppose that $\epsilon>0$. Since $(h, K, g) \in O M^{*}$ on 
$[a, b]$, there exists a subdivision $H$ of $[a, b]$ such that if $H^{\prime}=\left\{x_{i}\right\}_{0}^{n}$ is a refinement of $H$ and $0<i \leqq n$, then

$$
\left|f\left(x_{i}\right)-V\left(D_{i}, h, K, \Delta g\right)\right|<\epsilon / 2\left(1+m \int_{a}^{b}|d g|\right)
$$

where $m$ is a bound for $K$ and $D_{i}=\left\{x_{i}\right\}_{0}^{i}$. Let $x \in(a, b]$ and let $H^{\prime}=\left\{x_{i}\right\}_{0}^{n}$ be a refinement of $H$ such that $x \in H^{\prime}$. Let $x=x_{p}$ and $D=\left\{x_{i}\right\}_{0}^{p}$, where $0<p \leqq n$. Then there is a sequence $\left\{\epsilon_{i}\right\}_{1}^{p}$ such that $f\left(x_{i}\right)-\epsilon_{i}=V\left(D_{i}, h, K, \Delta g\right)$ for $0<i \leqq p$, where $D_{i}=\left\{x_{j}\right\}_{0}^{i}$. Let $A=$ $\left|a_{i j}\right|_{1}^{p}=V(D, h, K, \Delta g)$; then $A_{j}=V\left(D_{j}, h, K, \Delta g\right)$ for $j=1,2, \cdots, p$, and

$$
\begin{aligned}
f(x) & =f\left(x_{p}\right)=V(a, x ; h, K, d g)=V(D, h, K, \Delta g)+\epsilon_{p} \\
& =a_{p 1}+\sum_{j=2}^{p} A_{j-1} a_{p j}+\epsilon_{p} \\
& =\left(h_{p}+h_{0} K_{p, 0} \Delta g_{1}\right)+\sum_{j=2}^{p} V\left(D_{j-1}, h, K, \Delta g\right) K_{p, j-1} \Delta g_{j}+\epsilon_{p} \\
& =\left(h_{p}+h_{0} K_{p, 0} \Delta g_{1}\right)+\sum_{j=2}^{p}\left(f_{j-1}-\epsilon_{j-1}\right) K_{p, j-1} \Delta g_{j}+\epsilon_{p} .
\end{aligned}
$$

Since $h_{p}=h(x)$ and $h_{0}=f_{0}=f(a)$, then

$$
\begin{gathered}
\left|f(x)-h(x)-\sum_{1}^{p} f_{j-1} K_{n, j-1} \Delta g_{j}\right| \leqq\left|\epsilon_{p}\right|+\sum_{2}^{p}\left|\epsilon_{j-1} K_{n, j-1} \Delta g_{j}\right| \\
\leqq\left|\epsilon_{p}\right|+\left[\epsilon / 2 /\left(1+m \int_{a}^{b}|d g|\right)\right]<\epsilon .
\end{gathered}
$$

Since $x$ is an arbitrary element of $(a, b]$ and $H^{\prime}$ is an arbitrary refinement of $H$ containing $x$, then $f(x)-h(x)=(L) \int_{a}^{x} f(t) K(x, t) d g(t)$ for $x \in[a, b]$ and $(f, K, g) \in O A^{*}$ on $[a, b]$.

In the next three theorems, we prove a set of sufficient conditions for a function triple $(h, K, g)$ to belong to each of $O A^{*}, O M^{*}$ and $O M^{* *}$ and show that, with appropriate restrictions,

$$
V(a, b ; h, K, d g)=h(b)-(L) \int_{a}^{b} h(t) d V(t, b ; 1, K, d g) .
$$

The following lemma is used in the proofs of these theorems.

Lemma. Given. $f$ is a function from $R$ to $N$ and if $\epsilon>0$ then there is a subdivision $D=\left\{x_{i}\right\}_{0}^{n}$ of $[a, b]$ such that, if $0<i \leqq n$ and $x_{i-1}<x<y<$ $x_{i}$, then $|f(x)-f(y)|<\epsilon$. Conclusion. The function $f$ is quasicontinuous on $[a, b]$.

THEOREM 7. Given. (1) The functions $f$ and $K$ are bounded and 
$d g \in O B^{0}$ on $[a, b]$ and $F(x)=(L) \int_{a}^{x} f(t) K(x, t) d g(t)$ exists for $a \leqq x \leqq$ $b$; and (2) if $\epsilon>0$ then there is a subdivision $D=\left\{x_{i}\right\}_{0}^{n}$ of $[a, b]$ such that, if $0<i \leqq n$ and $x_{i-1}<x<y<x_{1}$ and $\left\{t_{t}\right\}_{0}^{m}$ is a refinement of $D$ such that $t_{s} \in\left\{t_{i}\right\}_{0}^{m}$ and $y=t_{s}$, then

$$
\left|\Sigma_{1}^{s} f\left(t_{t-1}\right)\left[K\left(x, t_{t-1}\right)-K\left(y, t_{t-1}\right)\right]\left[g\left(t_{i}\right)-g\left(t_{t-1}\right)\right]\right|<\epsilon .
$$

Conclusion. (1) The function $F$ is quasicontinuous on $[a, b]$; and (2) $(f, K, g) \in O A^{*}$ on $[a, b]$.

Proof of Conclusion 1. Suppose that $\epsilon>0$ and $M$ is a bound for $|f||K|$. There is a subdivision $D=\left\{x_{i}\right\}_{0}^{n}$ of $[a, b]$ such that, if $0<p \leqq n$ and $x$ and $y \in\left(x_{p-1}, x_{p}\right)$, then $\int_{x}^{y}|d g|<\epsilon / 4 M$ and, if $\left\{t_{i}\right\}_{0}^{m}$ is any refinement of $D$ and $y=t_{s}$, then

$$
\left|\sum_{1}^{s} f\left(t_{t-1}\right)\left[K\left(x, t_{t-1}\right)-K\left(y, t_{t-1}\right)\right]\left[g\left(t_{i}\right)-g\left(t_{i-1}\right)\right]\right|<\epsilon / 4 .
$$

Let $p$ be an integer and $x$ and $y$ be numbers such that $0<p \leqq n$ and $x$ and $y \in\left(x_{p-1}, x_{p}\right)$. There is a refinement $D^{\prime}=\left\{t_{i}\right\}_{0}^{m}$ of $D$ and integers $r$ and $s$ such that $x=t_{r}, y=t_{s}$ and such that $|A|<\epsilon / 4$ and $|B|<\epsilon / 4$, where

$$
\begin{aligned}
& A=F(x)-\Sigma_{1}^{r} f\left(t_{i-1}\right) K\left(x, t_{i-1}\right)\left[g\left(t_{i}\right)-g\left(t_{t-1}\right)\right], \quad \text { and } \\
& B=F(y)-\Sigma_{1}^{s} f\left(t_{i-1}\right) K\left(y, t_{i-1}\right)\left[g\left(t_{t}\right)-g\left(t_{i-1}\right)\right] .
\end{aligned}
$$

Hence,

$$
|F(y)-F(x)| \leqq|A|+|B|+|C|+|E|<\epsilon,
$$

where

$$
\begin{aligned}
& C=\Sigma_{1}^{r} f\left(t_{t-1}\right)\left[K\left(y, t_{t-1}\right)-K\left(x, t_{t-1}\right)\right]\left[g\left(t_{i}\right)-g\left(t_{i-1}\right)\right], \quad \text { and } \\
& E=\Sigma_{r+1}^{s} f\left(t_{i-1}\right) K\left(y, t_{i-1}\right)\left[g\left(t_{t}\right)-g\left(t_{t-1}\right)\right],
\end{aligned}
$$

and $|C|<\epsilon / 4$ and $|E|<\epsilon / 4$. Therefore, $F$ is quasicontinuous on $[a, b]$.

Proof of Conclusion 2. Let $\epsilon>0$ and $M$ be a bound for $|f||K|$. Since $F$ is quasicontinuous on $[a, b]$, then there is a subdivision $H_{1}=\left\{z_{i}\right\}_{0}^{m}$ of $[a, b]$ which is a refinement of the subdivision $D$ defined above and such that, if $0<p \leqq m$ and $z_{p-1}<x<y<z_{p}$, then $|F(x)-F(y)|<\epsilon / 4$. Let $H_{2}$ be an interpolating sequence for $H_{1}$ and let $H$ be a refinement of $H_{1} \cup H_{2}$ such that, if $H^{\prime}=\left\{y_{i}\right\}_{0}^{n}$ is a refinement of $H$ and $y_{q} \in H_{1} \cup H_{2}$, then 


$$
\left|F\left(y_{q}\right)-\Sigma_{1}^{q} f\left(y_{i-1}\right) K\left(y_{q}, y_{i-1}\right)\left[g\left(y_{i}\right)-g\left(y_{i-1}\right)\right]\right|<\epsilon / 4 \text {. }
$$

We now show that this subdivision $H$ satisfies the definition for $O A^{*}$. Let $H^{\prime}=\left\{t_{i}\right\}_{0}^{p}$ be a refinement of $H$ and let $x=t_{r} \in H^{\prime}$. If $x \in H_{1} \cup H_{2}$, then the $O A^{*}$ inequality $|\cdot|<\epsilon$ is satisfied. Suppose that $x \notin H_{1} \cup H_{2}$; then there exist $y=t_{s} \in H_{2}$ and $z_{j-1}, z_{j} \in H_{1}$ such that $x$ and $y \in\left(z_{j-1}, z_{j}\right)$. For convenience we will assume that $x<y$. Hence,

$$
\left|F(x)-\Sigma_{1}^{r} f\left(t_{i-1}\right) K\left(x, t_{i-1}\right)\left[g\left(t_{i}\right)-g\left(t_{i-1}\right)\right]\right| \leqq|A|+|B|+|C|+|E|<\epsilon,
$$

where $A=F(x)-F(y)$ and $B, C$ and $E$ are defined as in Conclusion 1 of this proof. If $x>y$, the steps would be similar. Therefore, $(f, K, g) \in$ $O A^{*}$ on $[a, b]$.

THEOREM 8. Given. The function $K$ is bounded on $[a, b] \times[a, b]$ and on $[a, b]$ the functions $h$ and $g$ have bounded variation, the set

$$
\left\{F_{q}\left|q \in[a, b], F_{q}=\int_{a}^{x}\right| d K(, q) \mid\right\}
$$

of functions is quasicontinuous uniformly and $F(x)=V(a, x ; h, K, d g)$ exists. Conclusion. (1) $F$ is quasicontinuous on $[a, b]$; and $(2)(h, K, g) \in$ $O M^{*}$ on $[a, b]$.

Proof of Conclusion 1. Suppose that $0<\epsilon<1$ and $m>1$ is a bound for $h$ and $K$; then there is a number $M$ which is an $m$-bound for $V(,,, \Delta g)$ on $[a, b]$ and a number $Q>1$ which has the properties stated in Theorem 5. There is a subdivision $D=\left\{x_{i}\right\}_{0}^{n}$ of $[a, b]$ such that, if $0<i \leqq n$ and $x_{i-1}<x<y<x_{i}$, then

$$
\begin{aligned}
& \int_{x}^{y}|d K(t, q)|<\epsilon / 8 m M\left(\int_{a}^{b}|d g|+1\right) \text { for } q \in[a, b], \\
& \int_{x}^{y}|d g|<\epsilon / 8 Q M, \text { and } \int_{x}^{y}|d h|<\epsilon / 8 M .
\end{aligned}
$$

Suppose that $0<i \leqq n$ and that $x_{i-1}<x<y<x_{i}$; then there is a refinement $\left\{z_{i}\right\}_{0}^{r}$ of $D$ such that $x=z_{p}$ and $y=z_{q}$ and such that $|F(x)-V(P, h, K, \Delta g)|<\epsilon / 8$ and $|F(y)-V(R, h, K, \Delta g)|<\epsilon / 8$, where $P=\left\{z_{i}\right\}_{0}^{p} \quad$ and $\quad R=\left\{z_{i}\right\}_{0}^{q}$. Let $\quad A=\left|a_{i j}\right|_{1}^{q}=V(R, h, K, \Delta g)$; then $V(P, h, K, \Delta g)=\left|a_{i j}\right|_{1}^{p}=A_{p}$.

Let $B=\left|b_{i j}\right|_{1}^{q}$ be the $q \times q$ determinant such that $b_{i j}=0$ for $p<j \leqq$ $i \leqq q$ and $b_{i j}=a_{i j}$ otherwise. It follows from Theorem 5 that 


$$
\begin{aligned}
|A-B| \leqq & Q \sum_{\imath=1}^{q} \sum_{\jmath=1}^{i}\left|a_{i j}-b_{\imath \jmath}\right|\left|g\left(z_{i+1}\right)-g\left(z_{\imath}\right)\right| \\
= & Q\left[\sum_{l=p+1}^{q-1} \Sigma_{\jmath=p+1}^{i}\left|a_{\imath j}\right|\left|\Delta g_{i+1}\right|+\sum_{\jmath=p+1}^{q}\left|a_{q \jmath}\right|\right] \\
= & Q\left[\sum_{l=p+1}^{q-1} \sum_{j=p+1}^{\prime}\left|K_{t, \jmath-1} \Delta g_{j}\right|\left|\Delta g_{\imath+1}\right|\right. \\
& \left.+\sum_{\jmath=p+1}^{q}\left|K_{q, \jmath-1} \Delta g_{j}\right|\right] \\
\leqq & Q\left[M\left(\int_{x_{p}}^{x_{q}}|d g|\right)^{2}+M \int_{x_{p}}^{x_{q}}|d g|\right]<\epsilon / 4 .
\end{aligned}
$$

Also, $B_{\jmath-1}=A_{j-1}$ and ${ }^{*} B_{p j}=a_{q j}$ (Th. 1f) for $j=1,2, \cdots, p$; therefore,

$$
\begin{aligned}
\left|B-A_{p}\right| & =\left|\sum_{\jmath=1}^{p} B_{\jmath-1}{ }^{*} B_{p \jmath}-\sum_{\jmath=1}^{p} A_{\jmath-1} a_{p j}\right| \\
& \leqq \sum_{\jmath=1}^{p}\left|A_{\jmath-1}\right|\left|{ }^{*} B_{p \jmath}-a_{p \jmath}\right| \leqq M \sum_{\jmath=1}^{p}\left|a_{q \jmath}-a_{p \jmath}\right| \\
& \leqq M\left[\left|h_{q}-h_{p}\right|+\left|h_{0}\right|\left|K_{q 0}-K_{p 0}\right|\left|\Delta g_{1}\right|+\sum_{\jmath=2}^{p}\left|K_{q, \jmath-1}-K_{p, \jmath-1}\right|\left|\Delta g_{j}\right|\right] \\
& \leqq M\left[\epsilon / 8 M+m \sum_{\jmath=1}^{p}\left(\epsilon / 8 m M\left(\int_{a}^{b}|d g|+1\right)\right)\left|\Delta g_{\jmath}\right|\right]<\epsilon / 4 .
\end{aligned}
$$

Hence,

$$
\begin{aligned}
|F(y)-F(x)| & \leqq|F(y)-A|+|A-B|+\left|B-A_{p}\right|+\left|A_{p}-F(x)\right| \\
& <\epsilon / 8+\epsilon / 4+\epsilon / 4+\epsilon / 8<\epsilon .
\end{aligned}
$$

The proof of Conclusion 2 is similar to the proof of Conclusion 2 of Theorem 7.

TheOREM 9. Given. The function $K$ is bounded on $[a, b] \times[a, b]$ and on $[a, b] g$ has bounded variation and $F(x)=V(a, b ; 1, K, d g)$ exists, where 1 denotes the identity function. Conclusion. (1) $F$ is quasicontinuous on $[a, b] ;(2)(1, K, g) \in O M^{* *}$ on $[a, b]$; and (3) if $d h \in O B^{0}$ on $[a, b]$, then $V(a, b ; h, K, d g)$ exists and is $h(b)-(L) \int_{a}^{b} h(t) d F(t)$.

Proof of Conclusion 1. Let $\epsilon>0$, let $M$ be a bound for $|K|$ and let $Q$ be a number having the properties defined in Theorem 5 . Since $d g \in O B^{0}$, there is a subdivision $D=\left\{x_{1}\right\}_{0}^{m}$ of $[a, b]$ such that, if $0<i \leqq m$ and $x_{t-1}<x<y<x_{t}$, then $\int_{x}^{y}|d g|<\epsilon / 6 Q M\left(1+\int_{a}^{b}|d g|\right)$. Suppose that $0<r \leqq m$ and $x_{r-1}<x<y<x_{r}$. Since $F(x)=V(x, b ; 1, K, d g)$ and $F(y)=V(y, b ; 1, K, d g)$ exist, then there exists a subdivision $R=\left\{z_{l}\right\}_{0}^{n}$ of $[x, b]$ and an integer $p$ such that $0<p<n$ and a subdivision $P=\left\{z_{l}\right\}_{p-1}^{n}$ of $[y, b]$ such that $x=z_{0}, \quad y=z_{p-1}, \quad|F(x)-V(R, 1, K, \Delta g)|<\epsilon / 6$, and $|F(y)-V(P, 1, K, \Delta g)|<\epsilon / 6$. 
Let $A=V(R, 1, K, \Delta g)=\left|a_{i j}\right|_{1}^{n}$ and $C=V(P, 1, K, \Delta g)=\left|a_{i j}\right|_{p}^{n}=$ ${ }^{*} A_{p}$; let $B=\left|b_{i j}\right|_{1}^{n}$ be the $n \times n$ determinant such that $b_{i 1}=a_{i p}$ for $p \leqq i \leqq n, b_{i j}=0$ for $1<j \leqq i \leqq p, b_{i j}=0$ for $p<i \leqq n$ and $2 \leqq j \leqq p$, and $b_{i j}=a_{i j}$ otherwise. In the following manipulations, $\left|\Delta g_{n+1}\right|=1$ and $\left|a_{i j}\right|$ denotes the norm of the element $a_{i j}$; hence,

$$
\begin{aligned}
|A-B| \leqq & Q \sum_{i=1}^{n} \sum_{j=1}^{i}\left|a_{i j}-b_{i j}\right|\left|\Delta g_{i+1}\right| \\
= & Q\left[\left|a_{n 1}-b_{n 1}\right|+\sum_{j=2}^{p}\left|a_{n j}\right|\right]+Q \sum_{i=p}^{n-1}\left|a_{i 1}-b_{i 1}\right|\left|\Delta g_{i+1}\right| \\
& +Q\left[\sum_{i=2}^{p} \sum_{j=2}^{i}\left|a_{i j}\right|\left|\Delta g_{i+1}\right|+\sum_{i=p+1}^{n-1} \sum_{j=2}^{p}\left|a_{i j}\right|\left|\Delta g_{i+1}\right|\right] \\
= & Q\left[\left|\left(1+K_{n 0} \Delta g_{1}\right)-\left(1+K_{n, p-1} \Delta g_{p}\right)\right|+\sum_{j=2}^{p}\left|K_{n, j-1} \Delta g_{j}\right|\right] \\
& +Q\left[\sum_{i=p}^{n-1}\left|\left(1+K_{i 0} \Delta g_{1}\right)-\left(1+K_{i, p-1} \Delta g_{p}\right)\right|\left|\Delta g_{i+1}\right|\right] \\
& +Q\left[\sum_{i=2}^{p} \sum_{j=2}^{i}\left|K_{i, j-1} \Delta g_{j}\right|+\sum_{i=p+1}^{n-1} \sum_{j=2}^{p}\left|K_{i, j-1} \Delta g_{j}\right|\left|\Delta g_{i+1}\right|\right] \\
\leqq & 2 Q M \int_{x}^{y}|d g|+Q M\left(\left|\Delta g_{1}\right|+\left|\Delta g_{p}\right|\right) \int_{a}^{b}|d g| \\
< & \quad+Q M \int_{x}^{y}|d g| \int_{a}^{b}|d g| \\
&
\end{aligned}
$$

It follows from Theorem 1f that $B={ }^{*} A_{p}=C$; hence,

$$
\begin{aligned}
|F(x)-F(y)| & \leqq|F(x)-A|+|A-B|+|B-C|+|C-F(y)| \\
& <\epsilon / 6+2 \epsilon / 3+0+\epsilon / 6=\epsilon .
\end{aligned}
$$

Therefore, $F$ is quasicontinuous on $[a, b]$.

The proof of Conclusion 2 is similar to the proof of Conclusion 2 of Theorem 7.

Proof of Conclusion 3. Suppose that $\epsilon>0$. Since $d h \in O B^{0}$ and $F$ is quasicontinuous, then $(R) \int_{a}^{b} d h F$ exists. Since $(R) \int_{a}^{b} d h F$ and $V(a, b ; 1, K, d g)$ exist and $(h, K, g) \in O M^{* *}$, there exists a subdivision $D$ of $[a, b]$ such that if $D^{\prime}=\left\{x_{i}\right\}_{0}^{n}$ is a refinement of $D$ and $0<i \leqq n$, then

$$
\left|(R) \int_{a}^{b} d h F-\Sigma_{1}^{n} \Delta h_{i} F_{i}\right|<\epsilon / 3
$$

and

$$
\left|F\left(x_{i}\right)-V\left(D_{i}, 1, K, \Delta g\right)\right|<\epsilon / 3\left(\int_{a}^{b}|d h|+1\right)
$$


for $i=0,1,2, \cdots, n$, where $D_{i}=\left\{x_{p}\right\}_{p=i}^{n}$. Let $D^{\prime}=\left\{x_{i}\right\}_{0}^{n}$ be a refinement of $D$ and let $D_{i}=\left\{x_{p}\right\}_{p=i}^{n}$ for $i=1,2, \cdots, n$. Also, let $V(D, h, K, \Delta g)=A=$ $\left|a_{\imath}\right|_{1}^{n}$ and let $V^{*}(D, h, K, \Delta g)=B=\left|b_{t \jmath}\right|_{1}^{n}$ be the $n \times n$ Volterra determinant such that (1) $b_{11}=a_{11}$, and (2) if $1<i \leqq n$, then $b_{t j}=a_{i j}-a_{t-1, j}$ for $j=1,2, \cdots, n$. Note that $A=\left|a_{i j}\right|_{1}^{n}$ can be transformed into $B=\left|b_{i j}\right|_{1}^{n}$ by adding the negative of the elements of the $n-1$ st row of $A$ to the $n$th row of $A$, the negative of the elements of the $n-2$ nd row to the $n-1$ st row, etc. Hence, $A=B$, and for $i=1,2,3, \cdots, n$, the determinant ${ }^{*} B_{i+1}$ can be transformed into $V\left(D_{\imath}, 1, K, \Delta g\right)$ by adding the elements of the first row of ${ }^{*} B_{t+1}$ to the 2 nd row, the elements of the new 2 nd row to the 3 rd row, etc. Hence, there exists an element $\alpha$ of $N$ such that $|\alpha|<\epsilon$ and

$$
\begin{aligned}
& V(D, h, K, \Delta g)=\left|b_{\imath \jmath}\right|_{1}^{n}=\sum_{i=1}^{n} b_{i j}{ }^{*} B_{i+1} \\
& =\left(h_{1}+h_{0} K_{10} \Delta g_{1}\right)^{*} B_{2}+\sum_{t=2}^{n}\left[\Delta h_{t}+h_{0}\left(K_{t 0}-K_{t-1,0}\right) \Delta g_{1}\right]^{*} B_{t+1} \\
& =h_{0}\left[\left(1+K_{10} \Delta g_{1}\right)^{*} B_{2}+\sum_{t=2}^{n}\left(K_{i 0}-K_{t-1,0}\right) \Delta g_{1}{ }^{*} B_{t+1}\right]+\sum_{t=1}^{n} \Delta h_{t}{ }^{*} B_{i+1} \\
& =h_{0} V(D, 1, K, \Delta g)+\sum_{t=1}^{n} \Delta h_{i} F\left(x_{i}\right)+\sum_{t=1}^{n} \Delta h_{t}\left[{ }^{*} B_{i+1}-F\left(x_{\imath}\right)\right] \\
& =h_{0} V(a, b ; 1, K, d g)+(R) \int_{a}^{b} d h F+\alpha \\
& =h(a) F(a)+\left.h(x) F(x)\right|_{a} ^{b}-(L) \int_{a}^{b} h d F+\alpha \\
& =h(b)-(L) \int_{a}^{b} h d F+\alpha .
\end{aligned}
$$

Therefore, $V(a, b ; h, K, d g)$ exists and

$$
\begin{aligned}
V(a, b ; h, K, d g) & =h(a) V(a, b ; 1, K, d g)+(R) \int_{a}^{b} d h F \\
& =h(b)-(L) \int_{a}^{b} h d V(t, b ; 1, K, d g) .
\end{aligned}
$$

In Theorem 11 we prove a set of sufficient conditions for the existence of the limit $V(a, b ; h, K, d g)$. Theorem 10 is a lemma which is used in the proof of Theorem 11.

THEOREM 10. Given. The symbols $n, r$ and $p$ represent positive integers, $p<n$, and $A=\left|a_{i j}\right|_{1}^{n}$ is an $n \times n$ Volterra determinant and $B=\left|b_{i j}\right|_{1}^{n+r}$ is an $(n+r) \times(n+r)$ Volterra determinant such that

(1) if $0<j \leqq i \leqq p$, then $b_{i j}=a_{i j}$;

(2) if $p<i \leqq p+r$ and $0<j \leqq p$, then $b_{i j}=a_{p j}$;

(3) if $p+r<i \leqq n+r$ and $0<j \leqq p$, then $b_{i j}=a_{i-r, j}$;

(4) if $p+r<i \leqq n+r$, then $\sum_{1=p+1}^{p+r+1} b_{i j}=a_{i-r, p+1}$; 
(5) if $p+r+1<j \leqq i \leqq n+r$, then $b_{i j}=a_{i-r, j-r}$; and

(6) if $p<j \leqq i \leqq p+r$, then $b_{i j}=0$.

Conclusion. $A=B$, where $A$ and $B$ represent elements of $N$.

Proof. Note that $A_{i}=B_{i}$ for $i=1,2, \cdots, p$ and ${ }^{*} A_{i}={ }^{*} B_{i+r}$ for $i>p+1$. It follows from (6) and (4) above that ${ }^{*} B_{i+1}={ }^{*} B_{p+r+1, i+1}$ for $i=p, p+1, \cdots, p+r$ and $\sum_{i=p}^{p+r *} B_{i+1}=\sum_{i=p}^{p+r *} B_{p+r+1, i+1}={ }^{*} A_{p+1}$. Hence,

$$
\begin{aligned}
B & =\sum_{j=1}^{p} B_{j-1}\left(\sum_{i=p}^{n+r} b_{i j}{ }^{*} B_{i+1}\right) \\
& =\sum_{j=1}^{p} B_{j-1}\left(\sum_{i=p}^{p+r} b_{i j}{ }^{*} B_{i+1}+\sum_{i=p+r+1}^{n+r} b_{i j}{ }^{*} B_{i+1}\right) \\
& =\sum_{j=1}^{p} A_{j-1}\left(\sum_{i=p}^{p+r} a_{p j}{ }^{*} B_{i+1}+\sum_{i=p+1}^{n} a_{i j}{ }^{*} A_{i+1}\right) \\
& =\sum_{j=1}^{p} A_{j-1}\left(a_{p j}{ }^{*} A_{p+1}+\sum_{i=p+1}^{n} a_{i j} A_{i+1}\right) \\
& =\sum_{j=1}^{p} A_{j-1} \sum_{i=p}^{n} a_{i j}{ }^{*} A_{i+1}=A,
\end{aligned}
$$

THEOREM 11. Given. $[a, b]$ is a number interval, $K$ is a bounded function from $R \times R$ to $N$ and $h$ and $g$ are functions from $R$ to $N$ such that $d g \quad$ and $\quad d h \in O B^{0} \quad$ on $[a, b], \quad \int_{a}^{b} \int_{a}^{b}|d K||d g||d g|=0 \quad$ and $\int_{a}^{b}|d K(b, t)||d g(t)|=0$. Conclusion. (1) $V(a, b ; h, K, d g)$ exists, and (2) if $\int_{a}^{b}|d K(, t)||d g(t)|=0$ uniformly on $[a, b]$, then on $[a, b]$ the function $f(x)=V(a, x ; h, K, d g)$ exists, $(h, K, g) \in O M^{*}$ and $f$ is the solution of the equation

$$
f(x)=h(x)+(L) \int_{a}^{x} f(t) K(x, t) d g(t) .
$$

Proof. We will show that the limit $V(a, b ; h, K, d g)$ exists by showing that the following Cauchy criterion condition is satisfied: if $\epsilon>0$ then there is a subdivision $D$ of $[a, b]$ such that, if $D^{\prime}$ is a refinement of $D$, then $\left|V(D, h, K, \Delta g)-V\left(D^{\prime}, h, K, \Delta g\right)\right|<\epsilon$. Let $\epsilon>0$ and let $M$ be a bound for $(1+|h|)(1+|K|)\left(1+\int_{a}^{b}|d g|\right)$ on $[a, b]$. It follows from Theorem 5 that there is a number $Q$ such that, if $U, W, u$ and $w$ are functions bounded by $M$ on $[a, b]$ and $D=\left\{x_{i}\right\}_{1}^{n}$ is a subdivision of $[a, b]$, then

$$
|A-B| \leqq Q \sum_{p=1}^{n} \sum_{j=1}^{p}\left|a_{p j}-b_{p j}\right|\left|g\left(x_{p+1}\right)-g\left(x_{p}\right)\right|,
$$

where $A=\left|a_{i j}\right|_{1}^{n}=V(D, u, U, \Delta g), \quad B=\left|b_{i j}\right|_{1}^{n}=V(D, w, W, \Delta g) \quad$ and $\left|\Delta g_{n+1}\right|=1$. 
Since $d g$ and $d h \in O B^{0}$ and $\int_{a}^{b} \int_{a}^{b}|d K||d g||d g|=0$ and $\int_{a}^{b}|d K(b, t)||d g(t)|=0$, there is a subdivision $D=\left\{x_{i}\right\}_{0}^{n}$ of $[a, b]$ such that

$$
\begin{gathered}
\sum_{i=1}^{n} \int_{x_{i-1}}^{x_{i}^{-}}|d g| \int_{x_{i-1}^{+}}^{x_{i}}|d g|<\epsilon / 9 M Q, \\
\sum_{i=1}^{n} \int_{x_{i-1}}^{x_{i}^{-}}|d h| \int_{x_{i-1}^{+}}^{x_{i}}|d g|<\epsilon / 9 Q, \text { and } \int_{a^{+}}^{x_{2}}|d g|<\epsilon / 18 M Q ; \\
\sum_{i=1}^{n} \sum_{j=1}^{i} M_{i j} \int_{x_{i-1}}^{x_{i}}|d g| \int_{x_{j-1}}^{x_{i}}|d g|<\epsilon / 9 M Q,
\end{gathered}
$$

where for each $i$ and $j, M_{i j}$ is the lub of $\left|K\left(x_{i-1}, x_{j-1}\right)-K(x, y)\right|$ for $x_{i-1} \leqq x<x_{i}$ and $x_{j-1} \leqq y<x_{j}$; and

$$
\sum_{1}^{n} M_{i} \int_{x_{i-1}}^{x_{i}}|d g|<\epsilon / 9 Q
$$

where for each $i, M_{i}$ is the lub of $\left|K\left(b, x_{i-1}\right)-K(b, x)\right|$ for $x_{i-1} \leqq x<x_{i}$.

Let $D^{\prime}=\left\{z_{i}\right\}_{0}^{m}$ be a refinement of $D, A=\left|a_{i j}\right|_{1}^{n}=V(D, h, K, \Delta g)$ and $B=\left|b_{i j}\right|_{1}^{m}=V\left(D^{\prime}, h, K, \Delta g\right)$. Let $\left\{n_{i}\right\}_{0}^{n}$ be the sequence of integers such that $x_{i}=z_{n_{i}}$ for $i=1,2, \cdots, n$. We now define an $m \times m$ determinant $C=\left|c_{i j}\right|_{1}^{m}$ such that $C=A$ and $|B-C|<\epsilon$ and, hence, $|A-B| \leqq$ $|A-C|+|C-B|<\epsilon$. In the following paragraphs, the symbols $h_{i}, K_{i j}$ and $\Delta g_{i}$ represent $h\left(z_{i}\right), K\left(z_{i}, z_{j}\right)$ and $g\left(z_{i}\right)-g\left(z_{i-1}\right)$, respectively.

Let $P_{1}$ be the set of integer pairs such that $i, j \in P_{1}$ iff $j=1$ and $1 \leqq i<n_{2}$. Let $c_{i j}=a_{11}$ for $i, j \in P_{1}$; then

$$
\begin{aligned}
\sum_{i, j \in P_{1}}\left|b_{i j}-c_{i j}\right|\left|\Delta g_{i+1}\right| & \leqq \sum_{i=1}^{n_{2}-1} 2 M\left|\Delta g_{i+1}\right| \leqq 2 M \int_{a^{+}}^{x_{2}}|d g| \\
& <2 M(\epsilon / 18 M Q)=\epsilon / 9 Q .
\end{aligned}
$$

Let $P_{2}$ be the set of integer pairs such that $i, j \in P_{2}$ iff $j=1$ and $n_{2} \leqq i<m$. If $i, j \in P_{2}$ and $2<p \leqq n$ and $n_{p-1} \leqq i<n_{p}$, then $c_{i j}=a_{p-1,1}$. Let $N_{p}=\left[n_{p-1}, n_{p}\right)$. Since $x_{0}=z_{0}=a$, then

$$
\begin{aligned}
\sum_{i, j \in P_{2}}\left|b_{i j}-c_{i j}\right|\left|\Delta g_{i+1}\right|=\sum_{p=3}^{n} \Sigma_{i \in N_{p}} \mid h\left(z_{i}\right)+h\left(z_{0}\right) K\left(z_{i}, z_{0}\right)\left(\Delta g_{1}\right) & \\
& -h\left(x_{p-1}\right)-h\left(x_{0}\right) K\left(x_{p-1}, x_{0}\right)\left[g\left(x_{1}\right)-g\left(x_{0}\right)\right]|| \Delta g_{i+1} \mid \\
= & \sum_{p=3}^{n} \Sigma_{i \in N_{p}} \mid\left[h\left(z_{i}\right)-h\left(x_{p-1}\right)\right]+h\left(x_{0}\right)\left\{K\left(z_{i}, z_{0}\right)\left[g\left(z_{1}\right)-g\left(z_{0}\right)\right]\right. \\
& \left.-K\left(x_{p-1}, x_{0}\right)\left[g\left(x_{1}\right)-g\left(x_{0}\right)\right]\right\}|| \Delta g_{i+1} \mid
\end{aligned}
$$




$$
\begin{aligned}
\leqq & \sum_{p=3}^{n} \Sigma_{i \in N_{p}}\left|h\left(z_{i}\right)-h\left(x_{p-1}\right)\right|\left|\Delta g_{i+1}\right| \\
& +\sum_{p=3}^{n} \Sigma_{i \in N_{p}}\left|h\left(x_{0}\right)\right|\left|K\left(z_{i}, x_{0}\right)-K\left(x_{p-1}, x_{0}\right)\right|\left|g\left(x_{1}\right)-g\left(x_{0}\right)\right|\left|\Delta g_{i+1}\right| \\
& +\left|g\left(z_{1}\right)-g\left(x_{1}\right)\right| \Sigma_{p=3}^{n} \Sigma_{i \in N_{p}}\left|h\left(x_{0}\right)\right|\left|K\left(z_{i}, z_{0}\right)\right|\left|\Delta g_{i+1}\right| \\
\leqq & \sum_{p=3}^{n} \int_{x_{p-1}}^{x_{p}^{-}}|d h| \int_{x_{p-1}^{+}}^{x_{p}}|d g| \\
& +\left|h\left(x_{0}\right)\right| \sum_{p=3}^{n} \Sigma_{i \in N_{p}} M_{p, 0}\left|g\left(x_{1}\right)-g\left(x_{0}\right)\right|\left|\Delta g_{i+1}\right| \\
& +(\epsilon / 18 M Q)\left|h\left(x_{0}\right)\right|\left|K\left(z_{i}, z_{0}\right)\right|\left(\int_{a}^{b}|d g|+1\right) \\
< & \epsilon / 9 Q+M(\epsilon / 9 M Q)+\epsilon / 9 Q=\epsilon / 3 Q,
\end{aligned}
$$

where $M_{p 0}$ is the lub of $\left|K\left(x_{p-1}, x_{0}\right)-K(x, y)\right|$ for $x_{i-1} \leqq x<x_{i}$ and $x_{j-1} \leqq y<x_{j}$.

Let $P_{3}$ be the set of integer pairs such that $i, j \in P_{3}$ iff $1<j \leqq n_{1}$ and $j \leqq i \leqq m$. Let $c_{i j}=0$ for $i, j \in P_{3}$; then

$$
\begin{aligned}
\sum_{i, j \in P_{3}}\left|b_{i j}-c_{i j}\right|\left|\Delta g_{i+1}\right|=\sum_{j=2}^{n_{1}} \sum_{i=j}^{m}\left|K\left(z_{i}, z_{j-1}\right) \Delta g_{j}\right|\left|\Delta g_{i+1}\right| \\
\leqq \\
\leqq \sum_{j=2}^{n_{1}} M\left|g\left(z_{j}\right)-g\left(z_{j-1}\right)\right| \leqq M \int_{a^{+}}^{x_{1}}|d g| \\
<M(\epsilon / 9 M Q)=\epsilon / 9 Q .
\end{aligned}
$$

Let $P_{4}$ be the set of integer pairs such that the pair $i, j \in P_{4}$ iff there is an integer $p$ such that $1<p \leqq n$ and $n_{p-1}<j \leqq i<n_{p}$. Let $c_{i j}=0$ for $i, j \in P_{4}$; then

$$
\begin{aligned}
\sum_{i, j \in P_{4}}\left|b_{i j}-c_{i j}\right|\left|\Delta g_{i+1}\right|=\sum_{i, j \in P_{4}}\left|K\left(z_{i}, z_{j-1}\right) \Delta g_{j}\right|\left|\Delta g_{i+1}\right| \\
\quad \leqq M \sum_{p=2}^{n} \sum_{i=n_{p-1+1}}^{n_{p}-1} \sum_{j=n_{p-1}+1}^{i}\left|g\left(z_{j}\right)-g\left(z_{j-1}\right)\right|\left|g\left(z_{i+1}\right)-g\left(z_{i}\right)\right| \\
\quad \leqq M \sum_{p=2}^{n} \int_{x_{p-1}}^{x_{p}^{-}}|d g| \int_{x_{p-1}^{+}}^{x_{p}}|d g|<M(\epsilon / 9 M Q) .
\end{aligned}
$$

Let $P_{5}$ be the set of integer pairs such that $i, j \in P_{5}$ iff $i=m$ and also $j=1$ or $n_{1}<j \leqq m$. Let $c_{m 1}=a_{n 1}=h\left(x_{n}\right)+h\left(x_{0}\right) K\left(x_{n}, x_{0}\right)\left[g\left(x_{1}\right)-g\left(x_{0}\right)\right]$ and, if $1<p \leqq n$ and $n_{p-1}<j \leqq n_{p}$, let $c_{m j}=K\left(x_{n}, x_{p-1}\right)\left[g\left(z_{j}\right)-g\left(z_{j-1}\right)\right]$. Since $z_{m}=x_{n}$ and $z_{0}=x_{0}$, then

$$
\begin{aligned}
\sum_{i, j \in P_{s}} \mid & b_{i j}-c_{i j}|=| b_{m 1}-c_{m 1}\left|+\sum_{p=2}^{n} \sum_{j=n_{p-1}+1}^{n_{p}}\right| b_{m j}-c_{m j} \mid \\
= & \mid h\left(z_{m}\right)+h\left(z_{0}\right) K\left(z_{m}, z_{0}\right)\left[g\left(z_{1}\right)-g\left(z_{0}\right)\right] \\
& -h\left(x_{n}\right)-h\left(x_{0}\right) K\left(x_{n}, x_{0}\right)\left[g\left(x_{1}\right)-g\left(x_{0}\right)\right] \mid \\
& +\sum_{p=2}^{n} \sum_{j=n_{p-1}+1}^{n_{p}} \mid K\left(z_{m}, z_{j-1}\right)\left[g\left(z_{j}\right)-g\left(z_{j-1}\right)\right] \\
& -K\left(x_{n}, x_{p-1}\right)\left[g\left(z_{j}\right)-g\left(z_{j-1}\right)\right] \mid
\end{aligned}
$$




$$
\begin{aligned}
\leqq & \left|h\left(z_{0}\right)\right|\left|K\left(z_{m}, z_{0}\right)\right|\left|g\left(x_{1}\right)-g\left(z_{1}\right)\right| \\
& +\sum_{p=2}^{n} \sum_{l}^{n_{\underline{p}}} \underline{n}_{p-1+1}\left|K\left(x_{n}, z_{l-1}\right)-K\left(x_{n}, x_{p-1}\right)\right|\left|g\left(z_{j}\right)-g\left(z_{j-1}\right)\right| \\
\leqq & M\left|g\left(x_{1}\right)-g\left(z_{1}\right)\right|+\sum_{p=2}^{n} \sum_{j=n_{p-1}+1}^{n_{p}} M_{p}\left|g\left(z_{J}\right)-g\left(z_{J-1}\right)\right| \\
\leqq & M(\epsilon / 18 M Q)+\sum_{p=2}^{n} M_{p} \int_{x_{p-1}}^{x_{p}}|d g|<\epsilon / 3 Q,
\end{aligned}
$$

where $M_{p}$ is the lub of $\left|K\left(b, x_{p-1}\right)-K(b, z)\right|$ for $x_{p-1} \leqq z<x_{p}$.

Let $P_{6}$ be the set of integer pairs such that $i, j \in P_{6}$ iff there are integers $p$ and $q$ such that $2 \leqq q<p \leqq n$ and such that $n_{p-1} \leqq i<n_{p}$ and $n_{q-1}<j \leqq n_{q}$. If $i, j \in P_{6}$ and $n_{p} \leqq i<n_{p+1}$ and $n_{q-1}<j \leqq n_{q}$, let $c_{l j}=$ $K\left(x_{p}, x_{q-1}\right)\left[g\left(z_{l}\right)-g\left(z_{l-1}\right)\right]$; then

$$
\begin{aligned}
& \sum_{l, j \in P_{6}}\left|b_{i j}-c_{l j}\right|\left|\Delta g_{i+1}\right| \\
& =\Sigma_{P_{b}}\left|K\left(z_{i}, z_{\jmath-1}\right) \Delta g_{\jmath}-K\left(x_{p-1}, x_{q-1}\right) \Delta g_{j}\right|\left|\Delta g_{i+1}\right| \\
& \leqq \sum_{p=3}^{n} \sum_{q=2}^{p-1} \sum_{l=n_{p-1}}^{n_{p}-1} \sum_{j=n_{q-1}}^{n_{q}}\left|K_{l, j-1}-K\left(x_{p-1}, x_{q-1}\right)\right|\left|\Delta g_{l}\right|\left|\Delta g_{i+1}\right| \\
& \leqq \Sigma_{P_{h}} M_{p q}\left|\Delta g_{\text {J }}\right|\left|\Delta g_{i+1}\right| \\
& \leqq \sum_{p=3}^{n} \sum_{q=2}^{p-1} M_{p q} \int_{x_{p-1}}^{x_{p}}|d g| \int_{x_{q-1}}^{x_{q}}|d g|<\epsilon / 9 Q,
\end{aligned}
$$

where $M_{p q}$ is the lub of $\left|K\left(x_{p-1}, x_{q-1}\right)-K(x, y)\right|$ for $x_{p-1} \leqq x<x_{p}$ and $x_{q-1} \leqq y<x_{q}$.

The determinant $\left|c_{i j}\right|_{1}^{m}$ can be reduced to the determinant $\left|a_{i j}\right|_{1}^{n}$ by the following steps.

(1) If $n_{1}>1$, use Theorem 1f and obtain a determinant of lower order.

(2) For each integer $p$ such that $2<p \leqq n$ and $n_{p}>n_{p-1}+1$, use Theorem 10 and the definition of the determinant $\left|c_{i j}\right|_{1}^{m}$ to obtain a determinant of lower order. Note that, if $1<n_{p} \leqq i<n_{p+1}$, then

$$
\sum_{l=n_{q-1}+1}^{n_{q}} c_{l j}=K\left(x_{p}, x_{q-1}\right)\left[g\left(x_{q}\right)-g\left(x_{q-1}\right)\right]=a_{p q} .
$$

Hence,

$$
\begin{aligned}
\mid B- & A|\leqq| B-C|+| C-A|=| B-C \mid \\
& \leqq Q \sum_{i=1}^{m} \sum_{j=1}^{t}\left|b_{\imath \jmath}-c_{i j}\right|\left|\Delta g_{i+1}\right| \\
& =Q\left(\sum_{r=1}^{6} \Sigma_{i, j \in P_{r}}\left|b_{\imath \jmath}-c_{\imath l}\right|\left|\Delta g_{i+1}\right|\right)<Q(\epsilon / Q)=\epsilon .
\end{aligned}
$$

Therefore, if $\epsilon>0$ then there is a subdivision $D$ of $[a, b]$ such that if $D^{\prime}$ is a refinement of $D$, then $\left|V(D, h, K, \Delta g)-V\left(D^{\prime}, h, K, \Delta g\right)\right|<\epsilon$; hence, the limit $V(a, b ; h, K, d g)$ exists. 
Suppose that $\int_{a}^{b}|d K(, t)||d g(t)|=0$ uniformly on $[a, b]$. If $a<x \leqq$ $b$, it follows from Conclusion 1 that $V(a, x ; h, K, d g)$ exists. We now prove that $(h, K, g) \in O M^{*}$ on $[a, b]$. Let $\epsilon>0$ and define a subdivision $D$ of $[a, b]$ in the same manner as in Conclusion 1 except that $\int_{a}^{b}|d K(, t)||d g(t)|=0$ uniformly is used in defining $D$ in place of $\int_{a}^{b}|d K(b, t)||d g(t)|=0$.

If $\left\{x_{i}\right\}_{0}^{n}$ is a refinement of $D$ and $0<p \leqq n$, then a repetition of the steps in the proof of Conclusion 1 shows that, if $Q^{\prime}$ is a refinement of $Q=\left\{x_{i}\right\}_{0}^{p}$, then

$$
\left|V\left(Q^{\prime}, h, K, \Delta g\right)-V(Q, h, K, \Delta g)\right|<\epsilon .
$$

Since $V\left(a, x_{p} ; h, K, d g\right)$ exists, there is a refinement $Q^{\prime}$ of $Q$ such that $\left|V\left(Q^{\prime}, h, K, \Delta g\right)-V\left(a, x_{p} ; h, K, d g\right)\right|<\epsilon$; hence,

$$
\begin{aligned}
& \left|V\left(a, x_{p} ; h, K, d g\right)-V(Q, h, K, \Delta g)\right| \\
& \quad \leqq\left|V\left(a, x_{p} ; h, K, d g\right)-V\left(Q^{\prime}\right)\right|+\left|V\left(Q^{\prime}\right)-V(Q)\right|<2 \epsilon .
\end{aligned}
$$

Therefore, $(h, K, g) \in O M^{*}$ on $[a, b]$. It follows from Theorem 3 that $f$ is bounded on $[a, b]$ and from Theorem 6 that $f$ is the solution on $[a, b]$ of the equation $f(x)=h(x)+(L) \int_{a}^{x} f(t) K(x, t) d g(t)$.

\section{REFERENCES}

1. C. W. Bitzer, Stieltjes-Volterra integral equations, Illinois J. Math., 14 (1970), 434-451.

2. - Convolution, fixed point, and approximation in Stieltjes-Volterra integral equations, J. Austral. Math. Soc., 14 (1972), 182-199.

3. D. B. Hinton, A Stieltjes - Volterra integral equation theory, Canad. J. Math., 18 (1966), 314-331.

4. J. A. Reneke, A product integral solution of a Stieltjes-Volterra integral equation, Proc. Amer. Math. Soc., 24 (1970), 621-626.

5. Continuity for Stieltjes - Volterra integral equations, Rev. Roumaine Math. Pures Appl., 17 (1972), 389-401.

Received October 15, 1974 and in revised form February 11, 1976. 


\section{PACIFIC JOURNAL OF MATHEMATICS}

\section{EDITORS}

RICHARD ARENS (Managing Editor)

University of California

Los Angeles, California 90024

\author{
R. A. Beaumont \\ University of Washington \\ Seattle, Washington 98105
}

\section{J. DugunduI}

Department of Mathematics University of Southern California Los Angeles, California 90007

D. Gilbarg and J. Milgram

Stanford University

Stanford, California 94305

\section{ASSOCIATE EDITORS}

E. F. BECKENBACH
B. H. NeumanN

F. Wolp
K. YoshidA

\section{SUPPORTING INSTITUTIONS}

UNIVERSITY OF BRITISH COLUMBIA

CALIFORNIA INSTITUTE OF TECHNOLOGY

UNIVERSITY OF CALIFORNIA

MONTANA STATE UNIVERSITY

UNIVERSITY OF NEVADA

NEW MEXICO STATE UNIVERSITY

OREGON STATE UNIVERSITY

UNIVERSITY OF OREGON

OSAKA UNIVERSITY

\author{
UNIVERSITY OF SOUTHERN CALIFORNIA \\ STANFORD UNIVERSITY \\ UNIVERSITY OF HAWAII \\ UNIVERSITY OF TOKYO \\ UNIVERSITY OF UTAH \\ WASHINGTON STATE UNIVERSITY \\ UNIVERSITY OF WASHINGTON \\ AMERICAN MATHEMATICAL SOCIETY
}

The Supporting Institutions listed above contribute to the cost of publication of this Journal, but they are not owners or publishers and have no responsibility for its contents or policies.

Mathematical papers intended for publication in the Pacific Journal of Mathematics should be in typed form or offset-reproduced (not dittoed). double spaced with large margins. Underline Greek letters in red, German in green, and script in blue. The first paragraph or two must be capable of being used separately as a synopsis of the entire paper. Items of the biblography should not be cited there unless absolutely necessary, in which case they must be identified by author and Journal, rather than by item number. Manuscripts, in duplicate, may be sent to any one of the four editors. Please classify according to the scheme of Math. Reviews, Index to Vol. 39. All other communications should be addressed to the managing editor, or Elaine Barth, University of California, Los Angeles, California, 90024.

100 reprints are provided free for each article, only if page charges have been substantially paid. Additional copies may be obtained at cost in multiples of 50 .

The Pacific Journal of Mathematics is issued monthly as of January 1966. Regular subscription rate: $\$ 72.00$ a year (6 Vols., 12 issues). Special rate: $\$ 36.00$ a year to individual members of supporting institutions.

Subscriptions, orders for back numbers, and changes of address should be sent to Pacific Journal of Mathematics, 103 Highland Boulevard, Berkeley, California, 94708.

PUBLISHED BY PACIFIC JOURNAL OF MATHEMATICS, A NON-PROFIT CORPORATION Printed at Jerusalem Academic Press, POB 2390, Jerusalem, Israel.

Copyright (C) 1976 Pacific Journal of Mathematics All Rights Reserved 


\section{Pacific Journal of Mathematics}

\section{Vol. 64, No. $2 \quad$ June, 1976}

Richard Fairbanks Arnold and A. P. Morse, Plus and times............. 297

Edwin Ogilvie Buchman and F. A. Valentine, External visibility ......... 333

R. A. Czerwinski, Bonded quadratic division algebras.............. 341

William Richard Emerson, Averaging strongly subadditive set functions in unimodular amenable groups. II .........................

Lynn Harry Erbe, Existence of oscillatory solutions and asymptotic behavior for a class of third order linear differential equations ............. 369

Kenneth R. Goodearl, Power-cancellation of groups and modules........ 387

J. C. Hankins and Roy Martin Rakestraw, The extremal structure of locally compact convex sets ...................................

Burrell Washington Helton, The solution of a Stieltjes-Volterra integral

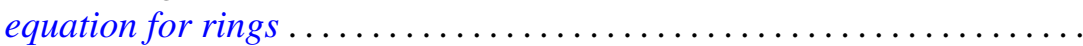

Frank Kwang-Ming Hwang and Shen Lin, Construction of 2-balanced

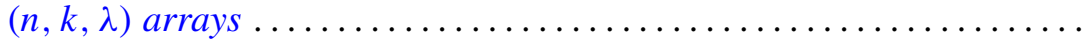

Wei-Eihn Kuan, Some results on normality of a graded ring ... 455

Dieter Landers and Lothar Rogge, Relations between convergence of series and convergence of sequences ......................... 465

Lawrence Louis Larmore and Robert David Rigdon, Enumerating immersions and embeddings of projective spaces ................

Douglas C. McMahon, On the role of an abelian phase group in relativized problems in topological dynamics..................

Robert Wilmer Miller, Finitely generated projective modules and TTF classes...

Yashaswini Deval Mittal, A class of isotropic covariance functions ...

Anthony G. Mucci, Another martingale convergence theorem ...

Joan Kathryn Plastiras, Quasitriangular operator algebras ...

John Robert Quine, Jr., The geometry of $p\left(S^{1}\right) \ldots \ldots \ldots$. 